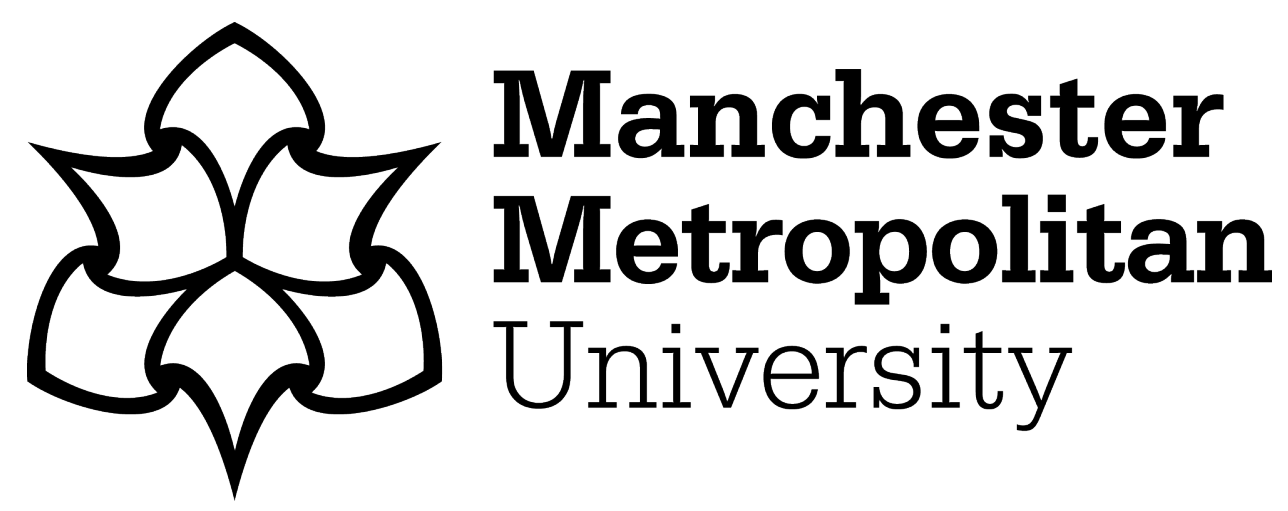

Di Feliciantonio, C and Gadelha, KB (2017) Affects, Bodies and Desire: 'Queering' Methods and Methodologies to Research Queer Migration. Tijdschrift voor Economische en Sociale Geografie, 108 (3). pp. 275-288. ISSN 0040-747X

Downloaded from: https://e-space.mmu.ac.uk/624255/

Version: Accepted Version

Publisher: Wiley

DOI: https://doi.org/10.1111/tesg.12235

Usage rights: Creative Commons: Attribution-Noncommercial 4.0

Please cite the published version 


\title{
Affects, bodies and desire: queering methods and methodologies to research queer migration
}

\author{
Cesare Di Feliciantonio ${ }^{1}$ and Kaciano B. Gadelha ${ }^{2}$
}

${ }^{1}$ Università di Roma 'La Sapienza', Department of Methods and Models for Space, Economics and Finance, Via del Castro Laurenziano 9, I-00161 Rome, Italy and

Katholieke Universiteit Leuven, Sociale en Economische Geografie - Afdeling Geografie, Department of Earth and Environmental Sciences (EES), Celestijnenlaan 200E, 3001 Leuven, Belgium

email: cesare.difeliciantonio@uniroma1.it

${ }^{2}$ Freie Universität Berlin, Institute for Latin American Studies, Rüdesheimer Str. 54-56, 14197

Berlin, Germany

email: kaciano.gadelha@fu-berlin.de

(Final draft of the paper published on Tijdschrift voor economische en sociale geografie, 108(3), 275-288)

\begin{abstract}
In this paper we discuss the main methodological issues raised by a research project we carried between 2012 and 2013 about Italian queer 'creative' migration in Berlin, focusing on the tensions among mobility/movement, desire, bodies, affects and fieldwork. Following an increasing international debate on the topic, the contribution discusses the (im)possibility to develop a queer method or methodology. We stress how queering methodologies and methods is not an ontological position pre-assumed when conducting research with queer-identified subjects, but is a process of dismantling taken-for-granted, stable, monolithic categories and identities. In order to do so, the paper discusses positionalities, situated knowledge and the different interactions- with both human and non-human actors- shaping the field. Through analysing body performances in the terms introduced by Diana Taylor, a politics of becoming emerges as a way to consider the relation between sexualities and spaces. The 'objects' of our research, i. e. queer migrants, can thus be reframed following Braidotti's conceptualization of the "nomadic subject" and Deleuze and Guattari's "desiring machines". Since they are shaped by affects, personal trajectories are exceptional and unique, composing new territorial materialities.
\end{abstract}

\section{Key-words:}


Queer methods and methodologies

Fieldwork

Positionalities

Body

Affects

Politics of becoming

\section{Introduction. Imagery and desire as (queer/creative) migration’ drivers}

Specific cities in specific times assume a transnational evocative power for specific groups of people, especially for subcultures, constituting a fertile background for their proliferation and reproduction. In this sense, Berlin holds its attractiveness as 'city of talents' (Krätke, 2004) featuring widespread underground culture, a wild nightlife and a welcoming environment for sexual dissidents (not only lesbian and gay people, but also BDSM practitioners, leather and fetish culture fans, etc). Many young 'creative' queer Italians have moved to Berlin in the last years, especially since the worsening of the current debt and financial crisis. Despite the lack of reliable data proving it, this is based on empirical evidence, considering, for instance, the new trend of 'Italian queer parties' in the city nightlife scene (e.g. Homopatik, Cocktail d'Amore, La Froceria). Between 2012 and 2013 we carried a research project on "The Queer Sound of Berlin" residing at the intersection between two stands of literature: queer migration and 'creative' migration, trying to make them complementary, one enlarging the perspective carried by the other. Why do Italian young queer 'creatives'- not just from small or countryside towns but mostly from large metropolitan areasmassively move towards Berlin? This was the leading question informing our research. When analysing these individual movements from different Italian metropolitan areas towards Berlin, our research aimed at exploring the role of imagery and desire in leading migration choices.

In this paper, we discuss the main methodological aspects of our project, focusing on the tensions among mobility/movement, affects, desire, bodies and fieldwork. By exploring these issues, we contribute to the increasing debate about queer methods and methodologies, firmly convinced that queering methodologies and methods is not an ontological position pre-assumed when conducting research with queer-identified subjects, but is a process of dismantling taken for granted, stable, monolithic categories and identities. This is linked to the foundational character of queer theory as "anti-normative and seeks to subvert, challenge and critique a host of taken for granted 'stabilities' in our social lives" (Browne and Nash, 2010: 7). Our intention is then to make queer theory inform all the methodology and methods-related concerns of our research work, rejecting any all- 
encompassing pretention. Indeed we believe that the reflections we bring are not only embedded in our subjective life paths, but they are time and place based, not just in one time, nor in one place (e. g. Katz, 1994, Nast, 1994). The writing time now overlaps and mixes with the time of the fieldwork, the time of notes taking and all the multiple times in between; the space of the room here overlaps with that of the parties we attended to conduct part of our research and with the private spaces we were introduced by our 'research partners' when collecting interviews and life histories. These overlapping times and spaces make our knowledge situated (e. g. Haraway, 1988, Rose, 1997), this being one of the key-concerns of the paper together with/being inseparable from the reflection on our positionalities. Before presenting the structure of the article, a premise is due: when referring to queer subjects in the paper, we use it as an umbrella term to include all those 'sexual deviants' exceeding the hegemonic forms of gender identity and sexual behaviour. So we trace a clearly open line, since we think no rigid divide can be traced in people's lives and experiences around gender and sexuality.

The remainder of the paper is made of six sections. In section 2, in order to frame our research project, we briefly review the literature on queer migration, emphasizing the critique of the 'coming-out journey' as a rural/urban movement and Gorman-Murray's call for 'downscaling' migration flows $(2007,2009)$. Section 3 reports the main insights of the international debate on queer methods and methodologies influencing our research, making necessary to reflect on our positionalities, understood as a significant practice, not as a way of fixing taken-for-granted identities. Following these insights, in section 4 we present the way we entered the field, conceived as resulting from a series of interactions with both human and non-human actors. This way, the field itself is re-signified, the participant observation becomes observant participation, bodies and affects gain a main relevance to understand queer migration. This centrality of the body is reinforced by considering the way the performances of actors shape new spatialities, this being the object of section 5. Indeed we bring the case of Tumulto, an Italian performer who moved to Berlin, as his performances reveal the tensions between the "archive" and the "repertoire" composing embodied knowledge, as theorized by Taylor (2003). Such a reconceptualization of migration through queer(ing) methodologies and methods call for reconsidering the relation between mobilities, affects and desire. We explore this relation in section 6 , through making reference to Braidotti's conceptualization of the "nomadic subject" as well as Deleuze and Guattari's "desiring machines". These theoretical tools result fundamental for rethinking the 'objects' of our research, i. e. queer migrants. Finally in the conclusions, after resuming the main argument of the paper, we emphasize the need to not decontextualize queer methodologies and methods, notably the politics of 
positionalities, from those power geometries making difficult or even dangerous for some subjects to position themselves.

\section{Framing the research project: 'downscaling' migration}

The choice to speak of 'queer migration' gives the possibility "to capture both the fluidity of sexual non-normativity (Browne, 2006, Giffney, 2004, Sullivan, 2003) and the disruptive nature of introducing non-heterosexual identities into presumptively heteronormative migration discourses (i. e., a process of 'queering')" (Lewis, 2012: 213). The literature on sexual dissidents' migration trajectories has usually overestimated two kinds of movements: the rural-urban and the global South- global North ones. The first reflects the 'coming-out journey' (Lewis, 2012), i. e. the widespread imagery featuring the city as "a beacon of tolerance and gay community, the country a locus of persecution and gay absence" (Weston, 1995: 262). According to Gorman- Murray, these accounts have become so common (e. g. Binnie, 2004, Cant, 1997, Parker, 1999, Weston, 1995) that "rural-to-urban movement begins to be seen as the foremost and archetypal trajectory of queer displacement, and other moves, like those between cities, are understood as not merely additional, but as fundamentally similar to moving from rural areas to cities, and hence not requiring further explanation or analysis" (2007: 108-109). In this model, the queer migrant is defined as an actor who migrates from an area of greater coercion, in terms of how to express and experience sexuality, to an area of greater openness (here the 'urban' is meant as an utopic space related to a certain kind of queer futurity, promising queer subjects a rendition of the sexual life in the anonymous and at the same time diverse territory of the big city) and sexual freedom represented by the metropolis. We share Gorman-Murray's criticism about this perspective being founded on a certain teleology, fixing not only identities but also classifying movements in a way that goes beyond the concrete practices, lived by queer subjects in the big city. Moreover, if rural and urban assume a form per se in relation to sexuality, the rural (regardless of where we are talking about, since this dichotomy has a teleological function) shall be the place of imprisonment of sexual dissidents that have to deal with various social constraints. By the leans of the migration process, the urban appears thus as the place of openness, which confers to queer subjects the capacity of assuming a cosmopolitan queer identity, global and closer to the mainstream culture that pushes the rural not emancipated yet sexual identities to get out of closet, in order to consolidate urban sexual identities, maybe anonymous but ever emancipated. It then becomes necessary to queer this kind of narrative in order to comprehend other practices of relocation. On the contrary, several studies have focused on the 
global South-global North movement (e. g. Das Gupta, 2006, Luibhéid, 2008, Manalansan IV, 2006) denouncing the heteronormativity pre-assumed in most migration and diaspora literature.

The movements we analysed in our research work exceed these trajectories, since they concern a global North metropolitan area/global North metropolitan area trajectory, all our research partners living in some of the main Italian metropolitan areas (e. g. Rome, Bologna, Padua) before moving to Berlin. In order to explore the role played by imagery and desire for these movements, we followed Gorman-Murray's idea (e. g. 2007, 2009) that it's necessary to 'downscale' migratory flows, focusing on the scale of the body. This perspective allows to avoid any economicism or reductionism left implicit in both perspectives of i) the 'creative' migrant moving where s/he can fully express their creativity and ii) the 'coming-out journey' of the queer in "quest for identity" (Knopp, 2004). Likewise Gorman-Murray, we see migratory flows as exceptional and individual movements based on a multiplicity of factors, thus leading us to opt for a qualitative methodology made of participant observation (at the main venues explicitly associated to the Italian queer community in Berlin), in-depth interviews and life histories collections with 15 self-identified queer subjects, realized between fall 2012 and spring 2013. Having framed our research project inside the larger debate about queer (and creative) migration explaining the used methodology, in the remainder of the paper we discuss how we queered the methodology and methods set for the project, starting from position ourselves within the debate on queer methods and methodologies.

\section{Is there anything like a 'queer' methodology or method? Conducting research on one's own community}

When considering the contribution of queer theory to the research practice and methodological reflection in social sciences, we can say that it concerned more the ontology and epistemology of knowledge rather than methods and methodologies themselves. Indeed as stated by Browne and Nash:

"looking at the wide range of queer scholarship that was developed since the early 1990's, it is clear that 'queer' approaches are deeply engaged in questioning the existence and 'knowability' of the social, particularly in various social normative claims. (...) If sexual and gender studies (and broader social theorising) create social fields, it follows that destabilising such theorizing, including through queer theorizing, and creating new social methods can create transformative politics through research" (2010: 14).

This reflects the initial concerns motivating De Lauretis when she spoke of a 'queer theory' as she aimed at opening a discussion on a theoretical order of multiple differences against a static, 
monolithic and homogenizing discourse on (homo)sexual difference (De Lauretis, 1991, Halperin, 2003). So a queer approach to social sciences constantly questions socially constructed concepts stressing the always changing and re-negotiating tendency of every human, while borders, locations and transitions are constantly moved and reshaped (Hammers and Brown III, 2004). Nevertheless, several efforts have been recently addressed towards a possible definition of a queer methodology and methods, notably in K. Browne and C. J. Nash book Queer Methods and Methodologies. Intersecting Queer Theories and Social Science Research. In the introduction to the collection, the editors distinguish between 'methodologies', as 'the logic that links the project's ontological and epistemological approaches to the selection and deployment of methods", and 'methods', as "what is 'done', that is, the techniques of collecting data" (2010: 10-11). However the essays forming the collection reveal the narrow boundaries of this distinction, showing how a queer methodology and a queer method open questions rather than giving answers. This undefined character is seen to originate from the fluid, unstable and multiple character of queer, "a term that can and should be redeployed, fucked with and used in resistant and transgressive ways, even if those ways are resisting what could, and some would argue already has, become a 'queer orthodoxy'" (ibid: 9). Indeed several voices had already denounced the increasingly institutionalized and normative tendencies within queer studies (Browne et al, 2010, Halberstam, 2003a, Halperin, 2003, Wilcox, 2006). Despite its foundational narrow and undefined boundaries, queer theory, likewise feminisms and post-structuralism, moved a strong critique to the idea of the "objective researcher", stressing the contingent, unstable and constituted character of knowledge production, including the "subject" of the research (e. g. Dixon and Jones III, 1996, England, 1994, Law, 2004, Sullivan, 2003). Moreover, the co-constitutive negotiation shaping the relation between 'subject' and 'objects' within the research process is unveiled (e. g. Gibson-Graham, 1994, Miles and Crush, 1993, Rose, 1997). Following these insights, we started to project and design our study interrogating ourselves about the (im)possibility to develop a queer methodology not located within a normative episteme which disaggregates the experiences of dissident sexualities in their models of knowledge. In this perspective, it appears essential to understand how heteronormativity is still implicit in many of our methodological principles, although they appear as 'queer'. Is it possible to theorize queerness, to produce a "queer theory" when we use very classificatory research methods fragmenting queer trajectories through the lens of age, race, sex, class and so forth? Sometimes these research methods resemble more the labelling of 'difference' in the neo-liberal model of co-optation that makes value of (sexual, ethnic, etc) difference (e. g. Binnie and Skeggs, 2004, Rushbrook, 2002) rather than critically discussing the categories themselves. How to interlock categories and avoid to reproduce an identitarian logics when interviewing people as "performative operators" or "trouble-making" 
(Jagger, 2008)? How to shake critically our methodological instruments, avoiding the production of new ontological entities, ready-made for the market labelling?

These questions made us aware of the role of our positionalities already in the conceiving phase of our research project. We (an Italian gay-identified guy living in Rome and a Brazilian gayidentified living in Berlin) have been connected with many actors in the Italian queer "creative" scene in Berlin. For the former, the Italian queer community in Berlin represent a continuum of the queer community he is attached to in Rome. Indeed in the last years most of the people- including several friends and comrades- animating the queer underground scene in Rome moved to Berlin, so the study evokes a series of personal, self-reflexive questions as he wondered many times about the eventuality to move himself to Berlin. Berlin then represents the space of (personal) possibility, as well as a missed futurity; these perceptions become even stronger and painful when facing the lack of possibilities in the Italian context of austerity. On the contrary, the latter researcher perceives the Italian queer community in Berlin as occupying a central part of his current life, as he attends most of the parties organized by the Italian queer community and he is in touch with many of these people. So our emotions, feelings, desires, bodies, expectations and lives not only influenced the research but constituted an indissoluble part, breaking the idea of the "right distance" in the research process and the linked assumption of the research subject/object dichotomy. This resonates with the sort of "emotional turn" featuring recently social sciences, notably geography (e. g. Ahmed, 2004, Anderson and Smith, 2001, Bondi, 2005, Bondi et al, 2007) as "going native" has finally started to find legitimacy within academia (e. g. Fuller, 1999, Kanuha, 2000). Nevertheless, this engagement of the researcher with their own communities often raises anxieties, dis-approval and charges of not being 'scientific' (Dahl, 2010). As brilliantly described by Duncan Fuller:

"When such involvement occurs, anxieties ensue. There is perhaps a tacit notion that to be 'committed', to be inside the group and work with it, results in the wholesale adoption of an uncritical, unquestioning position of approval in relation to that group and its actions; thus the standard of the research becomes questioned, its validity threatened (...) The inclusion within the research of the 'researcher as person' is interpreted as an apparent inability to distance him/herself from the events in which (s)he is participating, ultimately undermining the authority of the voice of the 'researcher as academic'" (1999: 221).

Albeit central in any research process, emotions, feelings, desire and bodies appear to gain an even increased importance when going native occurs within queer communities, as they usually are tight networks linking people both in the urban underground scene and transnationally (e. g. Dahl, 2010, Halberstam, 2005)- exactly as in our research project. Indeed Halberstam has noted how "minority subcultures in general tend to be documented by former or current members of the subculture rather 
than by "adult experts"” (2003b: 321). The result is that "work on queer subcultures tends to both rely on collaboration and furthermore, to challenge presumed distinctions between the researcher and her 'objects'" (Dahl, 2010: 150).

\section{Entering the field: situated knowledges and participant observation/observant participation}

Inspired by the debate briefly presented in the previous section, we started our research track by "queering the map" (Brown and Knopp, 2008), as we made an inventory of possible areas frequented by Italian migrants in the queer scene of Berlin. This mapping was already linked with our experiences as queer people in the city, which situates us in a discursive and embodied position in the city; indeed our feelings, intuitions, forms of exploring and discovering Berlin as a queer city or becoming-queer city played an important role in this regard. We here refer to ourselves not just as researchers, but also as social actors who experience the city along with others, establishing connections and differences with spaces and the other actors inhabiting them. This imposed a perspective beyond the classic "participant observation", in which the researcher enters the spaces lived by their interlocutors managing a neutral methodological distance, like a spectator who attends a performance but without being a performer or taking part in the performance. In our case, observation overlaps participation, making it a dirty participation, since we did not 'clean' those elements that could compromise the analysis according to the positivist model of knowledge. According to this very platonic and impersonal conception of knowledge, all those 'compromising elements' involving sensation (intuitions, feeling, affects) should be erased, as they belong to the field of inaccuracy. Can this overlap of the condition of observing over the experience inherent to the "participant observation" be applied to any object within the field of research on dissident sexualities and which are its limits?

In our case, mapping Berlin as an attractive city for Italian queer people started in the night scene of electronic music projects, already established in the queer scene, many devised by Italian producers and Djs in partnership with other local actors in Berlin. The fact that these projects have already been established as part of the queer scene in Berlin- many of them often appointed in the monthly calendar Siegessäule - shows how we are not referring to Italian ghettos of queer people in Berlin, but spaces within the metropolitan scene where the performance of queer migrant people takes place. In these spaces, where our bodies in motion grasped the cartographies of the queer scene in Berlin, we met our first interlocutors. As a field strategy, we decided to attend these parties, not

\footnotetext{
${ }^{1}$ It is a monthly local magazine advertising all LGBTQI public events in Berlin, with a printed edition freely available in bars, discos, saunas as well as online (www.siegessaeule.de).
} 
only by scheduling dates in a very programmatic manner, but also following our feelings, our intuitions, open our investigating ears, our inquiring skin to the flows of affects and sensations. We did know that this was not going to be a travel in a neutral territory, thus we would be touched by the field as affects link landscape with bodyscapes and soundscapes, queering the borders of our bodies, queering the way we interface with others. At the parties, much of what we observed was inscribed within the register of memory, being able to take only few notes in the darkness of a nightclub under several decibels of electronic and techno music. So we had the chance to talk to lots of people, one interlocutor introducing the other, opening the gates of the queer Italian migration world in Berlin. Afterwards we could arrange some contacts for interviews outside the nightlife situation. This experience served to situate us in two different moments: the moment of data collection through interviews, and the moment to be with our counterparts, in areas frequented by them. In the party situations, we left full space for our sensitivity working, permitting our bodies to grasp what would affect by its components: the music, the colours, the architecture, the ways of dressing, the interactions, the dancing, the drinking, the talking. It was time to situate ourselves within the field.

Is there a queer way to be in the field? Is it possible to queer the field, that field traditionally associated by anthropology to what is distant from us, i. e. the Other (Connors Jackman, 2010)? When fieldwork concerning our community and lives, where does it start and finish? Which are its boundaries? These self-reflexive issues made us understand how every knowledge is a perspective effect, since it is produced by subjects situated in time and space, negotiating different categories that confer meaning to established positions on the social field. All knowledge claims a situated condition, as Haraway (e. g. 1988, 1991) has brilliantly stressed. Our machines of knowledge are machines of vision, ways of seeing that objectify things. Indeed they are constructed devices to consolidate science as a regime of truth, they do not reveal the object as a whole. It takes us from squarely facing our bodies and positionalities, as a way of being in the world from which we are launched in the process of knowing. Under that tradition, the production of knowledge intertwines disembodiment with objectivity. However, at the departure point of theorization what could be ascertained is a fundamental singular point called perspective. Perspectivism has to do with a process of "queering the vision": only the "unknown", the strange, the 'inexplicable', the 'uncanny' can move our "will to knowledge", to say it in Foucauldian terms (1978). So our queer methodology challenges normalised bodies, breaking the silence that neutralizes what is between words and bodies. In this vein, queering methodologies exercises a breach of a certain paradigm that reifies the positions of investigator and investigated as hierarchical. This breakup is associated with a body that is not merely individual, but belonging to collective embodiment within the field of 
practice. Indeed the body is also an apparatus of vision, as the microscope to a biologist; this way, any view of a phenomenon becomes part of a position, an embodied experience:

"Embodiment is significant prosthesis; objectivity cannot be about fixed vision when what counts as an object is precisely what world history turns out to be about" (Haraway, 1991: 588).

The resulting queer methodology was activated with the body in motion, perambulating around the night scene. Since we were already familiar with these spaces, fieldwork involved for us not just the contact with new actors but also a rescue from our memories: our affective memory came to work. The situation on the field activated the body as a contact zone, producing knowledge between bodies, between the vibrating skin and the soundscape, the dark spaces and the sexualisation of bodies. This way, the observant participation entered the set of queer methodologies, contesting epistemic normativities that disavow the role of the body. A set of emotions, feelings, bodily interactions- taking place beyond verbal communication- shaped our data collection. This echoes Brown's observations about the importance of being affected by other human and non-human actors when in the field:

"the full, embodied thrill of the moment stems not just from our mutual exploration and enjoyment of each other's bodies, but from being fully present in that space. A whole set of affects and emotions were at play in this encounter, alongside the sensations of the touch, smell and sight of each other's body" (Brown, 2008: 919).

Tracking affects in migration flows is not an easy task, as they involve a continuous shift from concrete spaces to affections, perceptions and senses incorporated into spaces not verbalized during the time of the interview. We had to turn our ears in seismographs to affects- including ours-, in order to try to understand what kind of spatialities are delineated by migrants deciding to settle in Berlin. At parties like Cocktail D'Amore or Homopatik, we realized that the element of sound reverberated through the body by a dancing, not verbalised communication between actors: sweaty, drunken bodies, accelerated by the music, alcohol and other substances constituted a landscape connecting with human and non-human elements, such as one of cruising observed by Brown in his study on cruising spaces in London (2008). The walls, the architecture, the tangible and intangible elements find reconciled to human bodies. Following the anti-identitarian queer ontology recalled in section 3, we developed a critical perspective resizing the queer experience as a becoming, not fully centred around human actors (Knopp, 2004). In this perspective, rather than the ideal city of 'coming out' (Weston, 1995), Berlin is seen as resulting from the bodies shaping it even before the migration process, at the moment of figuring out the city we would like to live, as it is shaped by our imagery and desire. This movement towards Berlin then implies also a virtual and affective (urban) geography, a geography of 'becoming' setting up the connections among actors- human and 
non-human- and urban spaces- public, semi-public or personal. So our understanding of queer migration concerns becoming queer, encompassing the subjective cartographies in contact with these spaces that stimulate bodies through their concrete porosity, inviting for experiences of desire and sexuality, thus featuring a dimension of agency.

What is then the relationship between sexualities and space within a queer methodology? Classical perspectives classifying spaces according to the sexual identities of those living within them (e. g. Bell, 1991, Nash, 2013, Valentine, 1995) tend to fix 'queer' as an adjective given by the subjects, human social actors. Such a perspective can culminate in a "revival of the ghetto" (Brown, 2013) in times of a symbolism of space under the neoliberal agenda of cosmopolitanism (Binnie and Skeggs, 2004, Brown, 2004). On the other hand, while working at the intersection of human and nonhuman actors, spaces and subjectivities come into a relationship that is no longer anthropocentric, but coextensively: from space to body, from body to space, from the concrete domain of material objects to the emotional intensity of the skin. This result appears to echo Lorenz' consideration about "queer desire as method" (2009) when analysing the work of the artist Felix Gonzalez Torres, as the artist reconstructs the body of his partner in the space of the gallery but using nonhuman elements as wrappers of bonbons, without any visual similitude to a human body. Only the quantity brought a direct relationship with the body, such as the body weight of his partner, victim of AIDS, with the equivalent weight of wrappers comprising a geometric surface in the gallery. What Lorenz found in the work of this artist, making it a queer research methodology, is the development of another model to consider the relationship between sexuality and space, decentring the sexual symbolism that reduces sexual agency to the domain of identity. How to develop such a queer approach in social sciences research? For sure this requires a methodological ontology of openness giving the possibility to our research co-participants to express themselves through the tools they prefer, beyond oral narratives. In the next section we present the case of Tumulto, an Italian guy emigrated to Berlin, who played with the tensions between the "archive" and the "repertoire" as embodied in performance - following Taylor's conceptualization (2003)- to share his life history with us.

\section{Tumulto: the archives and the repertoires of Italian queer migration}

In order to problematize queer migration by connecting it to the strategies of territorialization in the new city, it results important to shed light on the body as a vector of confluence of different flows. This drives us to question how corporeality pertains to a hybrid domain in which the bodily surfaces are attached to spaces when non-bodily materialities extend the skin and vibrate with it. Following 
that, it is relevant to investigate what could be learnt with the body in its attachments to space. By asserting that something could be learnt with the body, we are referring not only to a set of knowledges that can be communicated through discourse and registers, such as interviews, documents, texts, but also to a set of ephemeral practices that shape the migrant body in movement, a set of affects, sensations, unspeakable inscriptions on the body which also form another kind of episteme.

Within her critique towards the literature on performance- that tends to reduce the analysis of performances to what could be documented- Diana Taylor (2003) produced a milestone contribution by formulating the concepts of "archive" and "repertoire" to the study of performance practices that build cultural memories. In order to challenge the logocentrism of Western 'modern' culture without recurring to Bourdieu's habitus because of its emphasis on meta-structures, Taylor analyses the dialectic tension between the registered texts of the "archive" and the embodied practice of the "repertoire" trying to "recognize the strengths and limitations of each system" (2003: 32). This way, the archival memory (traditionally thought as) permitting to resist against change and corruptibility is dialectically opposed to the embodied memory of the "repertoire", this being live exceeding the archive's capacity to capture and fix it. These categories reflect the traditional opposition in Western thought between written and spoken language, with written texts announcing "the disappearance of the performance practices involved in mnemonic transmission. Writing has served as a strategy for repudiating and foreclosing the very embodiedness it claims to describe" (ibid: 36). Nevertheless this opposition does not lead to a rigid, monolithic dualism; indeed "the repertoire, like the archive, is mediated. The process of selection, memorization or internalization, and transmission takes place within (and in turn helps constitute) specific systems of representation. Multiple forms of embodied acts are always present, though in a constant state of againness (...) Embodied and performed acts generate, record and transmit knowledge" (ibid: 21). The result is a notion of embodied practice and performance always in situ, simultaneously "real" and "constructed". The focus on embodied knowledge, as something that happens in the inbetweenness of words and bodies, combined with the insights coming from queer theory about decentring the subject as the core of signifying practices (e. g. Butler, 1990), leads to a new methodological orientation:

"It's not simply that we shift to the live as the focus of our analysis, or develop various strategies for garnering information, such as undertaking ethnographic research, interviews, and field notes. Or, even alter our hierarchies of legitimation that structure our traditional academic practice (such as book learning, written sources, and documents). We need to rethink our method of analysis. Here I will focus on one example. Instead of privileging texts and narratives, we could also look to 
scenarios as meaning-making paradigms that structure social environments, behaviours, and potential outcomes" (Taylor, 2003: 27-28).

What would be the scenarios of queer Italian migration in Berlin through this way? How are our interlocutors engaged in the world-making of performance (Shepard, 2010)? To which extent a specific walking through the city embodies performance? These questions were raised within our research project when we met Tumulto, a young Italian performer who had recently moved to Berlin. When sharing his personal narrative with us, Tumulto was constantly making reference to videos, images, advertisement cards or song, as performance- meant as the tension between the "archive" and the "repertoire"- was an indelible part of himself, constituting his own life-story. Indeed Tumulto (literally "tumult") is the name of his persona, the personage he incorporates in his performative practices, consisting basically in playing music (he performed as DJ in many venues of the queer scene in Berlin) while dressed up for vogue-ing on the street. Here it is not only about dragging, although some elements of drag could be observed, such as mixing clothes blurring the 'male'/'female'dress coding. It is much more an appropriation of the city by a performance challenging the dichotomy private/public space and questioning heternormativity in the public "catwalk" of light bodies on the streets as he appropriates 'inappropriately' the heteronormative "catwalk".

Performing in a video for an indie singer (figure 1), Tumulto presents his body in public spaces, he walks through many venues of Berlin handing a dog and a bunch of balloons, wearing a short skirt and an open jeans jacket. So the scene mixes a bear hairy body walking indifferently without paying attention around while curious eyes approach him with both fascination and estrangement. His body composes an archive, a bodily archive introducing us to other urban spaces, like some gay bars, bear parties and festivals or performances. His body is a walking archive through many non-queer spaces that become queer when he walks. He does not talk, he is just himself, thus he embodies the performance from the skin to the outfit. There is no truth to be revealed, no secret to be confessed. His repertoire of walking, looking and entering spaces shapes a strategy of knowledge: an experience of the city is being constructed when he acts. This way, the archive and the repertoire are enduringly connected. When we reflect on how we move through the city we can face many archives in movement, the rules of how to dress and how to behave in public spaces as prescribed by the unspoken power of heteronormativity (e. g. Hubbard, 2008). When Tumulto walks through the streets of Berlin, he blurs these codes and produces a tumult. This tumult is his repertoire, the power of his body in learning and producing other discourses about sexuality, sexual scenes and the city. 


\section{Mobilities, affects and desire: rethinking the research 'object'}

Recognizing the role of body performance as constituting the relation between space and sexuality to analyse queer migration calls necessarily into question the role of mobilities, affects and desire as shaping the 'object' of our research- queer people deciding to migrate from Italy to Berlin. In this sense, we refer to mobility not just as the physical displacement of social actors, but as a perspective dealing with the nomadic dimension of affects.

When recovering the idea of nomadism from Deleuze and Guattari (1987), Braidotti (e. g. 1994, 2006) reminds us that the nomad is a traveller in the field of intensities, this type of travel may involve or not physical displacement. According to her, the experience of nomadic subjects occurs in the affective sphere, where the emotions of the field are also situated. How often have we travelled from one city to another but it seems that we have not even left the departing place? The same hotels, the same fast food chains, the same global architectures: we travel miles but we feel like we have never left, identities remain fixed in their symbolic and emotional dimension. So Braidotti invites us to think of another nomadism: "Consciousness-raising and the subversion of set conventions define the nomadic state, not the literal act of travelling" (1994: 5).

Combining Braidotti's reconfiguration of the nomadic subject with the analytical framework of Gorman-Murray presented in section 2 about the body as a vector of migration, we can analyse queer migration throughout its subversive character, assuming the body as the starting point of movements. Likewise Braidotti, here we are not considering the dislocation of actors as limited to physical space, but we want to emphasize the internal movements of affection engendering new cartographies meant as "a theoretically-based and politically-informed reading of the present. A cartographic approach fulfils the function of providing both analytic and exegetical tools for critical thought and also creative theoretical alternatives" (Braidotti, 2013: 3). In this perspective, affects are drivers, they put bodies in motion. Commonly ignored in other theoretical approaches in migration studies, affects play here a very important role considering the reasons alleged by queer subjects to migrate. As we think of representative practices, here it is important to distinguish affects from emotions. The latters can be re-territorialized by significants, such as 'hate', 'love' or 'melancholia', thus they express a kind of affect turning into a symbolic territory. On the contrary, to define affects we find inspiration from Deleuze and Guattari (1984), considering them as sensitive flows, virtualities, forces with a nomadic power of re-territorialisation and deterritorialisation. In their critique of a Freudian and Lacanian conception of desire as lack, the French philosophers inverted the Freudian logic by which desire is interpreted as a foundational lack: desire becomes a flow that is not in a negative relationship with the social. Furthermore, desire 
is an active vector that generates worlds, so it is not by thinking in terms of absence that we grasp how desire works, but we can only understand the "world-making" power of desire if we consider it for its excess. The social overflows everywhere by the way "desiring machines" are producing excess. Such a category might become a useful tool here to redesign a queer methodology aimed at working with the dimension of desire we are defining here as affections.

The desiring machines are a composition of flows, forces that aggregate and dissipate. They work by the conjunction and disjunction of their elements. Relating this to the context of our research on Italian queer migration, how to understand the desire to migrate from one country to another? For instance, during interviews, our interlocutors often tried to frame their self-narratives within a linear script, as if the ambition to migrate had been imposed. It was necessary to develop together an alternative discourse highlighting the conjunctions and disjunctions that brought our co-participants to Berlin, trying to unveil uncertainties and turning points. So the process of mobility results associated with desire in the composition of imagined spaces that are not uniform, but specific markers of difference (e. g. gender, class, education, age, work experience) are operating in the lifetrajectories of these young queers. Although departing from and arriving to the same queer 'creative' scene, personal trajectories become exceptional and unique, as they are shaped by affects that compose new territorial materialities in combination to perceptions and conceptions. In this sense, affects move back and forth within processes of subjectification, mixing the present and the past and crossing the borders between the "archive" and the "repertoire".

\section{Conclusions: queer as an 'open methodology' of (relative) privilege and rupture}

In this paper we have discussed the main methodological issues raised by our research on Italian queer migration to Berlin as they interrogate the (im)possibility to develop a queer methodology, or better to queer methods and methodologies. Starting from an understanding of queer migration as a personal, peculiar bodily movement as theorized by Gorman-Murray (e. g. 2007, 2009) in opposition to the hegemonic narrative of the "coming-out journey" (Lewis, 2012), we have considered the body as the primary vector of our research methodology. Following the many insights originated within the international debate about queer methods and methodologies, we accorded a central role to our bodies, emotions, desires and affects in shaping the fieldwork, thus emphasizing the situated nature of knowledge and the need to critically discuss our positionalities. Such a non-normative perspective allowed us to enter the field recognizing it as resulting from the complex interactions between human and non-human actors; this way, "participant observation" became "observant participation", involving bodies and affects reframed queer migration within a 
geography of becoming, this being maybe the real essence (if any) of queer itself. A non-normative epistemology of non-fixity led us towards a methodological openness, so we explored the role of body performance to understand queer migration through the case of Tumulto as this highlights the tensions between the "archive" and the "repertoire" in the terms discussed by Taylor (2003). Such a reconceptualization of migration through queer(ing) methodologies and methods has involved the need to consider the relations linking mobilities, affects and desire as they shape the experiences of the "nomadic subjects"/“desiring machines" representing the "object" of our research project.

Throughout this methodological adventure the tight connection between affects and queerness gets unveiled and the non-identitarian character of queer thought results reinforced. This way, queer methods and methodologies, as well as queering methods and methodologies, emerge as a new politics of representation contesting those hegemonic 'representative orders' defining bodies and desires. This implies a process of becoming-other-than the hetero/homonormative order, even though it is in the realm of normativities that queerness gets shaped. These concerns call for the need to think of queer as an undefined positionality, as becoming-other, affective device for new cartographies of desire. Nevertheless, as showed by Braidotti (e. g. 2013), individual cartographies are always embedded within power geometries, so the exercise of positionalities is not always a possible task within the research process. Here we challenge the increasing institutionalization of the politics of positionalities as it has become a sort of compulsory requirement for scholars to be recognized as 'critical' enough; for instance, Robert Vanderbeck has noticed how "ostensibly reflexive fieldwork narratives often afford male researchers the opportunity to publicly affirm their masculine prowess" (2005: 389). Through recalling different situations experienced when conducting research with adolescents, his account reveals how position yourself in fieldwork can be painful, harmful and even dangerous if you do not embody a hegemonic social model. This goes far beyond a sense of failure that is perceived by the (queer/feminist) researcher when writing about reflexivity and positionalities (Rose, 1997), although failure can represent a familiar feeling for queer subjectivities (Halberstam, 2011). However "calls for researchers to write reflexively about gender, positionality and performance essentially ask those who deviate from hegemonic gender norms to disclose uncomfortable details about their interactions. Within the context of a masculinist and heterosexist discipline, this is a risky proposition, and one which deserves a far wider discussion than has been the case to date" (Vanderbeck, 2005: 398-399).

So the methodological openness and the politics of becoming featuring queer theory must be conceived as opening up new perspectives and possibilities that challenge normative binary orders without hiding the (relative) privilege implied by the exercise of positionalities, as people embodying non-hegemonic social models not always can afford it. 


\section{References}

Ahmed, S. (2004) The Cultural Politics of Emotion. Edinburgh: Edinburgh University Press.

Anderson, K. and Smith, S. (2001) Emotional Geographies, Transactions of the Institute of British Geographers, 26(1), pp. 7-10.

Arruzza, C. (2015) Gender as Social Temporality: Butler (and Marx), Historical Materialism,23(1), pp. 28-52.

Bell, D. (1991) Insignificant others: lesbian and gay geographies, Area, 23(4), pp. 323-329.

Binnie, J. (2004) The Globalization of Sexuality. London: Sage.

Binnie, J. and Skeggs, B. (2004) Cosmopolitan knowledge and the production and consumption of sexualized space: Manchester's gay village, The Sociological Review, 52(1), pp. 39-61.

Bondi, L. (2005) Making Connections and Thinking through Emotions: Between Geography and Psychotherapy, Transactions of the Institute of British Geographers, 30(4), pp. 433-448.

Bondi, L., Davidson, J. and Smith, M. (Eds.) (2007) Emotional Geographies. Aldershot: Ashgate. Braidotti, R. (1994) Nomadic Subjects: Embodiment and Sexual Difference in Contemporary Feminist Theory. New York: Columbia University Press.

Braidotti, R. (2006) Transpositions: On Nomadic Ethics. Cambridge: Polity Press.

Braidotti, R. (2013) Oxford talk, May 2013, online available: http://www.lmh.ox.ac.uk/getattachment/3f8c8c36-d2a7-4554-a612-079274c7bfa4/Writing-as-aNomadic-Subject-PRESENTATION.pdf.aspx [last visit: 08/04/2015]

Brown, G. (2004) Cosmopolitan camouflage: (post-)gay space in Spitalfields, East London, in J. Binnie, J. Holloway, S. Millington and C. Young (Eds.) Cosmopolitan Urbanism, pp. 130-145. New York: Routledge.

Brown, G. (2008) Ceramics, clothing and other bodies: affective geographies of homoerotic cruising encounters, Social \& Cultural Geography, 9(8), pp. 915-932.

Brown, M. (2013) Gender and sexuality II. There goes the gayborhood?, Progress in Human Geography, online first.

Brown, M. and Knopp, L. (2008) Queering the Map: The Productive Tensions of Colliding Epistemologies, Annals of the Association of American Geographers, 98(1), pp. 40-58.

Browne, K. (2006) Challenging queer geographies, Antipode, 38(5), pp. 885-893.

Browne, K. and Nash, C. J. (2010) Queer Methods and Methodologies: An Introduction, in K. Browne and C. J. Nash (Eds.) Queer Methods and Methodologies. Intersecting Queer Theories and Social Science Research, pp. 1-23. Aldershot: Ashgate. 
Browne, K., Munt, S. and Yip, A. (Eds.) (2010) Queer Spiritual Spaces: Sexuality and Sacred Places. Aldershot: Ashgate.

Butler, J. (1990) Gender Trouble: Feminism and the Subversion of Identity. New York: Routledge. Cant, B. (Ed.) (1997) Invented Identities? Lesbians and Gays Talk About Migration. London: Cassel.

Connors Jackman, M. (2010) The Trouble with Fieldwork: Queering Methodologies, in K. Browne and C. J. Nash (Eds.) Queer Methods and Methodologies. Intersecting Queer Theories and Social Science Research, pp. 113-128. Aldershot: Ashgate.

Dahl, U. (2010) Femme on Femme: Reflections on Collaborative Methods and Queer Femme-inist Ethnography, in K. Browne and C. J. Nash (Eds.) Queer Methods and Methodologies. Intersecting Queer Theories and Social Science Research, pp. 143-166. Aldershot: Ashgate.

Das Gupta, M. (2006) Unruly Immigrants: Rights, Activism, and Transnational South Asian Politics in the United States. Durham: Duke University Press.

De Lauretis, T. (1991) Queer Theory: Lesbian and Gay Sexualities, differences: a Journal of Feminist Cultural Studies, 3(2), pp. iii-xviii.

Deleuze, G. and Guattari, F. (1984) Anti-Oedipus: Capitalism and schizophrenia. London: The Athlone Press.

Deleuze, G. and Guattari, F. (1987) A Thousand Plateaus. Minneapolis: University of Minnesota Press.

Dixon, D. P. and Jones III, J. P. (1996) For a supercalifragilisticexpialidocious scientific geography, Annals of the Association of American Geographers, 86, pp. 767-779.

England, K. (1994) Getting personal: reflexivity, positionality and feminist research, The Professional Geographer, 46(1), pp. 80-89.

Foucault, M. (1978) The Will to Knowledge. Westminster: Penguin Books.

Fuller, D. (1999) Part of the action, or 'going native'? Learning to cope with the 'politics of integration', Area, 31(3), pp. 221-227.

Gibson-Graham, J. K. (1994) 'Stuffed if I know!' Reflections on post-modern feminist social research, Gender, Place \& Culture: A Journal of Feminist Geography, 1(2), pp. 205-224.

Giffney, N. (2004) Denormatizing queer theory: more than simply lesbian and gay studies, Feminist Theory, 5(1), pp. 73-78.

Gorman-Murray, A. (2007) Rethinking queer migration through the body, Social \& Cultural Geography, 8(1), pp. 105-121.

Gorman-Murray, A. (2009) Intimate mobilities: emotional embodiment and queer migration, Social \& Cultural Geography, 10(4), pp. 441-460. 
Halberstam, J. (2003a) Reflections on Queer Studies and Queer Pedagogy, Journal of Homosexuality, 45(2-4), pp. 361-364.

Halberstam, J. (2003b) What's that smell? Queer temporalities and subcultural lives, International Journal of Cultural Studies, 6(3), pp. 313-334.

Halberstam, J. (2005) In a Queer Time and Place: Transgender Bodies, Subcultural Lives. New York: New York University Press.

Halberstam, J. (2011) The Queer Art of Failure. Durham: Duke University Press.

Halperin, D. M. (2003) The Normalization of Queer Theory, Journal of Homosexuality, 45(2-4), pp. 339-343.

Hammers, C. and Brown III, A. D. (2004) Towards a feminist-queer alliance: a paradigmatic shift in the research process, Social Epistemology: A Journal of Knowledge, Culture and Policy, 18(1), pp. 85-101.

Haraway, D. (1988) Situated knowledges: The science question in feminism and the privilege of partial perspective, Feminist Studies, 14(4), pp. 575-599.

Haraway, D. (1991) Simians, Cyborgs and Women. New York: Routledge.

Hubbard, P. (2008) Here, There, Everywhere: The Ubiquitous Geographies of Heteronormativity, Geography Compass, 2(3), pp. 640-658.

Jagger, G. (2008) Judith Butler: Sexual Politics, Social Change and the Power of the Performative. Abingdon: Taylor \& Francis.

Kanuha, V. K. (2000) "Being” Native versus "Going Native”: Conducting Social Work Research as an Insider, Social Work, 45(5), pp. 439-447.

Katz, C. (1994) Playing the field: questions of fieldwork in geography, The Professional Geographer, 46(1), pp. 67-72.

Knopp, L. (2004) Ontologies of place, placelessness, and movement: queer quests for identity and their impacts on contemporary geographic thought, Gender, Place \& Culture: A Journal of Feminist Geography, 11(1), pp. 121-134.

Krätke, S. (2004) City of Talents? Berlin's Regional Economy, Socio-Spatial Fabric and 'Worst Practice' Urban Governance, International Journal of Urban and Regional Research, 28(3), pp. 511-529.

Law, J. (2004) After Method: Mess in Social Science Research. London: Routledge.

Lewis, N. (2012) Remapping disclosure: gay men's segmented journeys of moving out and coming out, Social \& Cultural Geography, 13(3), pp. 211-231.

Lorenz, R. (2009) Körper ohne Körper. Queeres Begehren als Methode/Bodies without Bodies. Queer Desire as Method, in B. Paul and J. Schaffer (Eds.) Mehr(wert) queer. Visuelle Kultur, Kunst 
und Gender-Politiken/ Queer Added (Value). Visual Culture, Art and Gender Politics, pp. 135-164. Bielefeld: transcript.

Luibhéid, E. (2008) Queer/Migration: An Unruly Body of Scholarship, GLQ: A Journal of Lesbian and Gay Studies, 14(2-3), pp. 169-190.

Manalansan IV, M. F. (2006) Queer Intersections: Sexuality and Gender in Migration Studies, International Migration Review, 40(1), pp. 224-249.

Miles, M. and Crush, J. (1993) Personal narratives as interactive texts: collecting and interpreting migrant life-histories, The Professional Geographer, 45(1), pp. 83-95.

Nash, C. J. (2013) The age of the "post-mo"'? Toronto's gay Village and a new generation, Geoforum, 49, pp. 243-252.

Nast, H. (1994) Opening remarks on 'Women in the field', The Professional Geographer, 46(1), pp. 54-66.

Parker, R. (1999) Beneath the Equator: Cultures of Desire, Male Homosexuality and Emerging Gay Communities in Brazil. New York: Routledge.

Rose, G. (1997) Situating knowledges: positionality, reflexivities and other tactics, Progress in Human Geography, 21(3), pp. 305-320.

Rushbrook, D. (2002) Cities, Queer Space, and the Cosmopolitan Tourist, GLQ: A Journal of Lesbian and Gay Studies, 8(1-2), pp. 183-206.

Shepard, B. (2010) Queer Political Performance and Protest. New York: Routledge.

Sullivan, N. (2003) A Critical Introduction to Queer Theory. Armadale: Melbourne Publishing.

Taylor, D. (2003) The archive and the repertoire. Performing cultural memory in the Americas.

Durham: Duke University Press.

Valentine, G. (1995) Out and about: geographies of lesbian landscapes, International Journal of Urban and Regional Research, 19(1), pp. 96-112.

Vanderbeck, R. (2005) Masculinities and Fieldwork: Widening the Discussion, Gender, Place \& Culture: A Journal of Feminist Geography, 12(4), pp. 387-402.

Weston, K. (1995) Get thee to a big city: sexual imagery and the great gay migration, GLQ: $A$ Journal of Lesbian and Gay Studies, 2(2), pp. 253-277.

Wilcox, M. (2006) Outlaws or in-laws? Queer theory, LGBT studies, and religious studies, Journal of Homosexuality, 52(1-2), pp. 73-100. 
Figure 1. Scene taken from the video Starman by Sally Saphiro feat. Sonic Youth in which Tumulto performs.

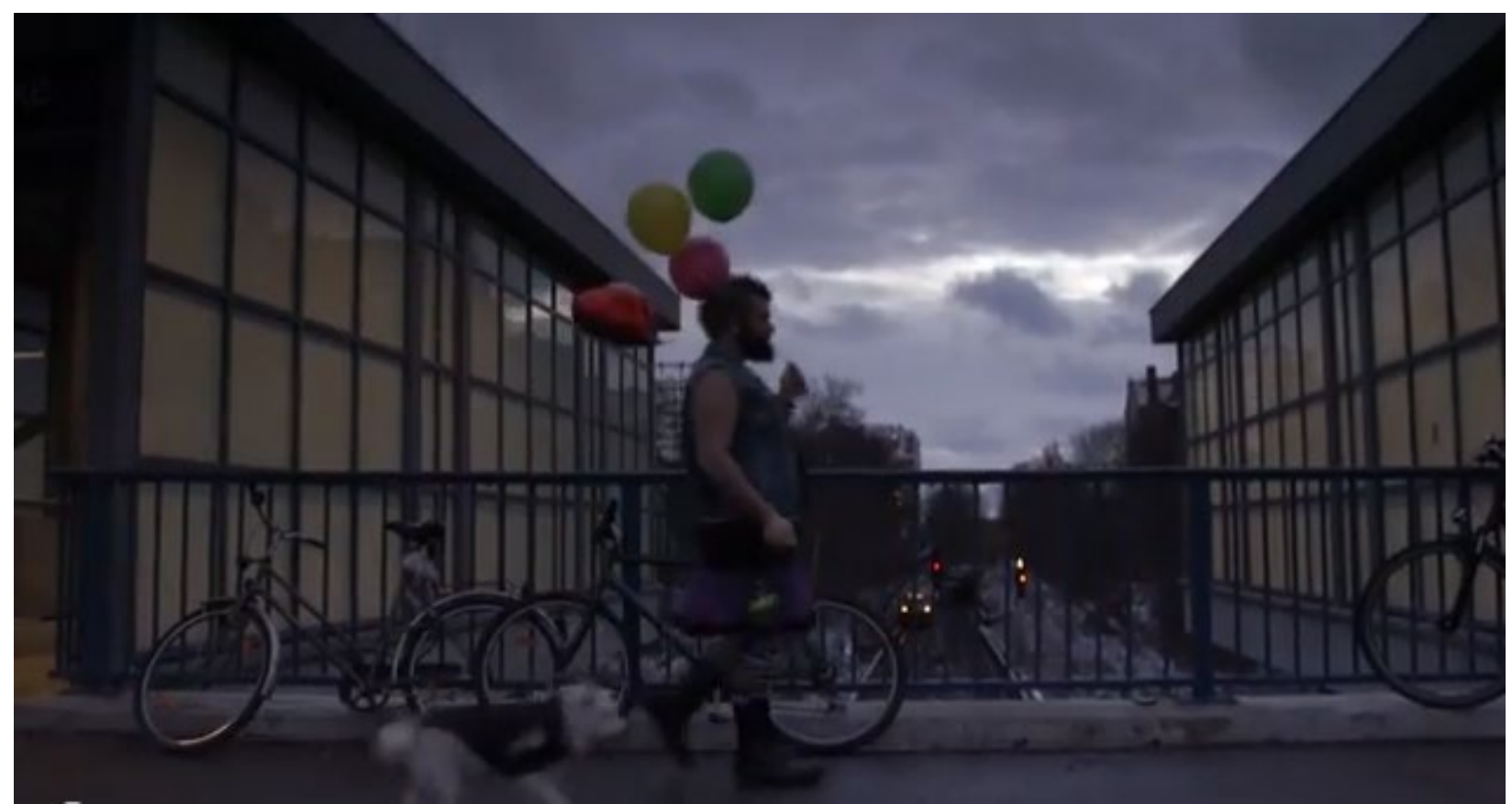

